\title{
BIBLIOGRAFIA PRAC NAUKOWYCH PROFESORA JANA ZABŁOCKIEGO
}

\section{Monografie:}

Użyczenie w klasycznym prawie rzymskim, Warszawa 1980, ss. 193 maszynopisu.

Kompetencje 'patres familias' $i$ zgromadzeń ludowych $w$ świetle 'Noctes Atticae’ Aulusa Gelliusa, Warszawa 1990, ss. 183.

Rozważania o procesie rzymskim w 'Noctes Atticae’ Aulusa Gelliusa, Warszawa 1999, ss. 190.

\section{Opracowania źródel:}

Ustawa XII Tablic. Tekst - tłumaczenie - objaśnienia (wspólnie z M. Zabłocką), Warszawa 2000, ss. 81; wyd. 2, Warszawa 2003; wyd. 3, Warszawa 2013.

\section{Podręczniki:}

Publiczne prawo rzymskie. Skrypt wraz z wyborem źródeł (wspólnie z A. Tarwacką), Warszawa 2005, ss. 181.

Publiczne prawo rzymskie (wspólnie z A. Tarwacką), Warszawa 2011, ss. 340.

\section{Artykuly:}

‘Commodatum rei suae’, «Prawo Kanoniczne» 24.3-4/1981, s. 257-264.

'Commodare habitationem', «Prawo Kanoniczne» 25.3-4/1982, s. 199-209. 
Korzystanie z rzeczy uzyczonej w prawie rzymskim, «Prawo Kanoniczne» 26.3-4/1983, s. 181-212.

'Actio commodati' w prawie rzymskim, «Prawo Kanoniczne» 27.34/1984, s. 197-222.

'Sacrorum detestatio' $w$ prawie rzymskim, «Prawo Kanoniczne» 29.1-2/1986, s. 265-282.

'Consortium ercto non cito' w 'Noctes Atticae' Aulusa Gelliusa, «Prawo Kanoniczne»» 31.33-4/1988, s. 271-182.

'Si mulier vinum bibit condemnatur', «Prawo Kanoniczne» 32.1-2/ 1989, s. 223-232.

Appunti sulla 'sacrorum detestatio', «Bullettino dell'Istituto di Diritto Romano» 92-93/1989-1990 [wyd.1993], s. 523-541.

Appunti sul 'testamentum mulieris', «Bullettino dell'Istituto di Diritto Romano» 94-95/1991-1992 [wyd.1994], s. 157-179.

'Leges de plebiscitis', «Prawo Kanoniczne» 35.1-2/1992, s. 237246.

'In decem mensibus gigni hominem', «Prawo Kanoniczne» 35.3-4/ 1992, s. 197-210.

'Si morbus aevitasve vitium escit', «Prawo Kanoniczne» 37.3-4/ 1994, s. 47-57.

Talionwświetle 'NoctesAtticae'Aulusa Gelliusa, «PrawoKanoniczne» 38.3-4/1995, s. 231-244.

Rodzina rzymska w świetle 'Noctes Atticae'Aulusa Gelliusa, [w:] Rodzina w spoleczeństwach antycznych $i$ wczesnym chrześcijaństwie. Literatura, Prawo, epigrafika, sztuka. Praca zbiorowa pod redakcja Juliusza Jundziłla, Bydgoszcz 1995, s. 45-57.

'Iudex qui iuravit sibi non liquere', «Prawo Kanoniczne» 39.3-4/ 1996, s. 215-226. 
The Image of a Roman Family in 'Noctes Atticae' by Aulus Gellius, «Pomoerium. Studia et Commentarii ad Orbem Classicum Spectantia» 2/1996, s. 47-58.

Henryk Kupiszewski, professore dell'Accademia di Teologia Cattolica di Varsavia, [w:] Le droit romain et le monde contemporain. Mélanges a la mémoire de Henryk Kupiszewski, Varsovie 1996, s. 25 33.

'Postumus' w 'Noctes Atticae' Aulusa Gelliusa, «Prawo Kanoniczne» 40.1-2/1997, s. 255-262.

Diritto romano nella Facolta di Diritto Canonico della Accademia di Teologia Cattolica di Varsavia, [w:] VII Colloquio dei romanisti dell'Europa Centro-Orientale e d'Italia, Universita di Roma «La Sapienza» 3-5 dicembre 1998, s. 1-10.

Matżeństwo konkordatowe, «Studia Iuridica» 37/1999, s.191-206.

Appunti sull' 'officium iudicis' nelle 'Noctes Atticae', [w:] Au-delà des fontierès. Mélanges de droit romain offers à Witold Wołodkiewicz, II, Varsovie 2000, s. 1115-1126.

Ze studiów filozofii Aulusa Gelliusa w Atenach, [w:] Profesorowi Janowi Kodrębskiemu 'in memoriam', pod red. Anny Pikulskiej-Robaszkiewicz, Łódź 2000, s. 465-474.

Procedura esecutiva nella legge delle XII tavole, [w:] VIII Colloquio dei romanisti dell'Europa Centro-Orientale e d'Italia, «Le persone nel sistema del diritto romano. La difesa dei debitori. Lo studio e l'insegnamento del diritto romano», Vladivostok, 3-7 ottobre 2000, Vladivostok 2000, s. 1-27.

Zgoda małżeńska $w$ prawie rzymskim, [w:] 'Honeste vivere'... Księga pamiatkowa ku czci Profesora Władysława Bojarskiego, Toruń 2001, s. 303-312.

Postepowanie egzekucyjne w ustawie XII tablic, [w:] Czynić sprawiedliwość w miłości. Księga pamiątkowa od Uniwersytetu Kardynata Stefana Wyszyńskiego dla Jego Eminencji Józefa Kardynała Glempa 
w dwudziesta rocznice postugi Prymasowskiej, zebrał i opracował Waldemar Chrostowski, Warszawa 2001, s. 310-334.

Illeciti delle donne romane, «Ius Antiquum»1(8)/2001, s. 75-80.

Prof. dr hab. Henryk Kupiszewski (1927-1994), prawnik, [w:] Ocalić od zapomnienia. Profesorowie Akademii Teologii Katolickiej w Warszawie we wspomnieniach wychowanków, Warszawa 2002, s. 90-95.

Il giurista del dopo Duemila. Appunti polacchi, [w:] Convengo internazionale. "Flaminio Mancaleoni (1867-1951) e gli studi di diritto romano tra ottocento e novecento. Prospettive nel XXI secolo", «Diritto@Storia. Rivista internazionale di Scienze Giuridiche e Tradizione Romana»1/2002.

Ex bona fide nella formula del comodato, [w:] Il ruolo della bona fede oggettiva nell'esperirnza giuridica storica e contemporanea. Atti del Convegno internazionale di studi in onore di Alberto Burdese, (Padova - Venezia - Treviso, 14-15-16 giugno 2001), a cura di Luigi Garofalo, IV, Milano 2003, s. 453-463.

'Patria communis' $i$ społeczności lokalne, [w:] Wielokulturowość polskiego pogranicza. Ludzie - Idee - Prawo, Białystok 2003, s. 129132.

Klauzula 'ex bona fide' w fomutce komodatu, «Zeszyty Prawnicze» 3.2/2003, s. 343-355.

'Ecclesia vivit lege romana', [w:] Giovanni Paolo II. La vie della giustizia. Ommaggio dei giuristi a Sua Santità nel XXV anno di pontifcato, a cura di Aldo Loiodice e Massimo Vari, Roma 2003, s. 119-120.

'Leges de plebiscitis'. Equiparazione i 'plebiscita' ai 'leges', [w:] Forum Romanum. Doklady III mieżunarodnoj konferencji. Rimskoe czastnoe i publicznoe pravo, Moskva 2003, s. 15-18.

Prawo rzymskie na Wydziale Prawa Kanonicznego Akademii Teologii Katolickiej w Warszawie, [w:] 'Semel Deo dedicatum non est ad usum humanos ulterius transferendum'. Ksiega pamiatkowa dedyko- 
wana ks. prof. dr hab. Julianowi Kałowskiemu MIC z okazji siedemdziesiątej rocznicy urodzin, Warszawa 2004, s. 671-688.

Capacità giuridica del nascituro nel diritto civile polacco, «Revista de Doctrina. 'Ius Commume omnium'» 1/2005. (La Plata), wyd. w formie elektronicznej: www.iuscommune omnium.com.ar/]

'Consensus facit nuptias', [w:] Marriage. Ideal - Law - Practice. Procedings of a conference held in memory of Henryk Kupiszewski, Warsaw 2005, [wyd. 2006] s. 235-247.

'Adrogatio' в римском праве, [w:] Римское частное и публичное право: многовековой опыт развития европейского права. IV Международная конфернция по римскому праву, Москва-Иваново (Суздаль), 25-30 июня 2006 г., Иваново 2006, s. 114-118.

La pena del taglione nel diritto Romano, [w:] 'Fides, humanitas, ius', Studii in onore di Luigi Labruna, VIII, Napoli 2007, s. 5990-6009.

The Intellectual Background of Aulus Gellius, «Diritto@Storia. Rivista internazionale di Scienze Giuridiche e Tradizione Romana» $6 / 2007$

'Adrogatio' nel dirito romano, [w:] 'Leges Sapere'. Studia i prace deddykowane Profesorowi Januszowi Sondlowi w pięćdziesiata rocznice pracy naukowej, pod red. Wacława Uruszczaka, Pauliny Święcickiej i Andrzeja Kremera, Kraków 2008, s. 719-732.

'Adrogatio' w prawie rzymskim', [w:] W trosce o rodzinę. Księga Pamiątkowa ku czci Profesor Wandy Stojanowskiej, Warszawa 2008, s. 599-615.

Rzymskie Studia Aulusa Gelliusa, «Acta Universitatis Wratislaviensis, Prawo» 305/2008. Studia historycznoprawne. Tom poświęcony pamięci Profesora Edwarda Szymoszka, pod. red. A. Koniecznego, s. 425-433.

'Consortium vitae', [w:] 'Finis legis Christus'. Ksiega pamiątkowa dedykowana Księdzu Profesorowi Wojciechowi Góralskiemu z okazji 
siedemdziesiątej rocznicy urodzin, red. J. Wroceński, J. Krajczyński, II, Warszawa 2009, s. 1327-1335.

'Consortium vitae', [w:] XII Colloquio dei romanisti dell'Europa Centro-Orienatle e dell'Asia, Irkustk 14-16 ottobre 2009. Raccolta di materiali scientifici, Irkutsk 2009, s. 44.

Le più antiche forme del testamento romano, [w:] 'Ius romanum schola sapientiae', Pocta Petrovi Blahovi k 70. narodeninám, Trnava 2009, s. 549-560.

The Roman Family in Light of 'Noctes Atticae' [artykuł z j. włoskiego na j. chiński przetłumaczył Li Wensheng], «Xiamen University Law Review» 7/2005 [wyd. 2010], s. 293-301.

'Polish Civil Code' in the Past, Present and Future, (wraz z A. Gawrysiak-Zabłocką) [artykuł z j. włoskiego na j. chiński przetłumaczył Xu Guodong], «Xiamen University Law Review» 7/2005 [wyd. 2010], s. 302-317.

Appunti sulla codificazione del diritto in Polonia, (wraz z A. Gawrysiak-Zabłocką), «Diritto@Storia. Rivista internazionale di Scienze Giuridiche e Tradizione Romana»8/2009.

Appunti sul Codice Civile Polacco, (wraz z A. Gawrysiak-Zabłocką), «Diritto@Storia. Rivista internazionale di Scienze Giuridiche e Tradizione Romana» 8/2009.

Rzymskie korzenie prawa kanonicznego, [w:] 'Ars boni et aequi' Księga pamiątkowa dedykowana Księdzu profesorowi Remigiuszowi Sobańskiemu z okazji osiemdziesiątej rocznicy urodzin, red. J. Wroceński, H. Pietrzak, Warszawa 2010, s. 587-594.

Najstarsze formy testamentu rzymskiego, [w:] O prawie i jego dziejach ksiegi dwie. Studia ofiarowane profesorowi Adamowi Lityńskiemu $w$ czterdziestopieciolecie pracy naukowej i siedemdziesięciolecie urodzin, red. M. Mikołajczyk, J. Ciągwa, P. Fiedorczyk, A.Stawarska-Rippel, T. Adamczyk, A. Drogoń, W. Organiściak, K. Kuźmicz, I, Białystok-Katowice 2010, s. 137-145. 
Pozycja prawna 'nasciturusa' w polskim prawie cywilnym, [w:] Kregu nowożytnej i najnowszej historii ustroju Polski. Ksiega dedykowana Profesoroowoi Marianowi Kallasowi, red. S. Godek, D. Makiłła, M. Wilczek-Karczewska, Warszawa 2010, s. 829-835.

Procedura esecutiva nella Legge delle XII Tavole, [w:] Studi in onore di Antonio Metro, a cura di C. Russo Ruggeri, VI, Napoli 2010, s. 513-538.

'Leges votate' nelle assemblee popolari [w:] Convegno internazionale "diritto romano privato e diritto romano pubblico": teoria e prattica, Xiamen 23-27.10.2010, Xiamen 2010, s. 8-12.

'Leges votatae’ nelle assemblee popolari, «Diritto@Storia. Rivista internazionale di Scienze Giuridiche e Tradizione Romana»10/20112012, = 'Leges votatae' na zgromadzeniach ludowych, Diritto@Storia»10/2011-2012.

Uchwaty rzymskich zgromadzeń ludowych, [w:] 'Regnare, gubernare, administrare’. Prawo i władza na przestrzeni wieków. Prace dedykowane profesorowi Jerzemu Malcowi z okazji 40-lecia pracy naukowej, red. S. Grodziski, A. Dziadzio, Kraków 2012, s. 3-15.

\section{Recenzje:}

Rec. (Pierluigi Zannini, Spunti critici per una storia del 'commodatum', Milano 1983), «Prawo Kanoniczne» 28.1-2/1985, s. 232-234.

Rec. (Francesco De Martino, Diritto privato e società romana, Roma 1982), «Prawo Kanoniczne» 28.3-4/1985, s. 320-321.

Rec. (Leo Peppe, Posizione giuridica e ruolo sociale della donna in et repubblicana, Milano 1984), «Prawo Kanoniczne» 29.3-4/1986, s. 295-297.

Rec. (Stownik kultury antycznej. Grecja. Rzym. Pod red. Lidii Winniczuk, wyd. IV, Warszawa 1986), «Prawo Kanoniczne» 30.3-4/1987, s. 298-301. 
Rec. (Sebastiano Tafaro, 'Pubes'e 'viripotens' nella esperienza giuridica Romana, Bari 1988), «Prawo Kanoniczne» 35.1-2/1992, s. 271-273.

Rec. (Andrzej Sokala, 'Lenocinium' w prawie rzymskim, Toruń 1992), «Prawo Kanoniczne» 36.1-2/1993, s. 261-263.

Rec. (Władysław Bojarski, Wojciech Dajczak, Andrzej Sokala, Przewodnik do ćwiczeń z prawa rzymskiego, red. Władysław Bojarski, Toruń 1990), «Prawo Kanoniczne» 36.1-2/1993, s. 247-250.

Rec. (Luigi Garofalo, Appunti sul diritto criminale nella Roma monarchica e repubblicana, Padova 1990), «Prawo Kanoniczne» 36.34/1993, s. 209-211.

Rec. (Adam Łukaszewicz, 'Aegyptiaca Antoniniana'. Działalność Karakalli w Egipcie (215-216), Warszawa 1993), «Prawo Kanoniczne» 37.1-2/1994, s. 271-273.

Rec. (Harold Ramon Gavernet, Mario Antonio Mojer, El Romano - La Tierra - Las Armas. Evolucion historica des las Instituciones del Derecho Romano, La Plata 1992), «Prawo Kanoniczne» 37.3-4/1994, s. 285-287.

Rec. (Michael Peachin, 'Iudex vice Caesaris'. Deputy Emperors and the Administration of Justice during the Principate = Heidelberger Althistorische Beiträge und Epigraphische Studien, Bd.XXI), Stuttgart 1996), «The Journal of Jouristic Papyrology» 26/1996, s. 211-213.

Rec. (Maria Laura Astarita, La cultura nelle 'Noctes Atticae'. Centro di studi sull'antico cristianesimo, Universita di Catania, Catania 1993), «Prawo Kanoniczne» 40.1-2/1997, s. 310-312.

Rec. (Roberto Fiori, 'Homo Sacer'. Dinamica politico-costituzionale di una sanzione giuridico religiosa, Università di Roma «La Sapienza». Pubblicazioni dell'Istituto di Diritto Romano e dei Diritti dell'Oriente e Mediterraneo, Jovene Editore, Napoli 1996), «Prawo Kanoniczne» 42.3-4/1999, s. 259-262. 
Rec. (Krzysztof Amielańczyk, Rzymskie prawo karne w reskryptach cesarza Hadriana, Wydawnictwo Uniwersytetu Marii Curie-Skłodowskiej, Lublin 2006), «Zeszyty Prawnicze» 7.2/2007, s. 355-363.

Rec. (Renata Świrgoń-Skok, Nieruchomość i zasady akcesji według prawa rzymskiego, Rzeszów 2007, ss.196) «Zeszyty Prawnicze» 8.1/2008, s. 395-399.

\section{Sprawozdania. Nekrologi.}

Wyktad Prof. Sebastiano Tafaro, «Prawo Kanoniczne» 34.3-4/1991, s. 285-286.

Giornata italo-polacca di diritto romano a Jeziory Mate, «Index. Quaderni camerti di studi romanistici» 21/1993, s. 653.

Henryk Kupiszewski (1927-1984), «Prawo Kanoniczne» 37.34/1994, s. 3-6.

Giornate italo-polacche di diritto romano a Zajączkowo, "Index. Quaderni camerti di studi romanistici» 23/1995, s. 707.

Henryk Kupiszewski *13.1.1927 +3.4.1984, «Orbis Iuris Romani» 3/1997, s. 117-120.

Prawo rzymskie ponad granicami (Jubileusz pięćdziesięciolecia pracy naukowej Profesora Witolda Wołodkiewicza), «Palestra» 44.7-8/ 2000, s. 199-203.

VIII Colloquio dei romanisti dell'Europa centro-orientale e d'Italia. Vladivostok 5-7 ottobre 2000, «Zeszyty Prawnicze» 1/2001, s. 191-195 [= Materiali 4 - VIII Colloquio dei romanisti dell'Europa centro-orientale e d'Italia, Vladivostok, 5-7 ottobre 2000, Roma 2002, s. 81-85].

VIII Kolokwium Romanistów Europy Centralno-Wschodniej i Włoch we Wtadywostoku, 5-7 października 200 r. - Studio e insegnamento del diritto romano. La persona nel sistema del diritto romano. La difesa dei debitori, «Studia Iuridica» 40/2002, s. 309-312. 
I Sesja Międzynarodowej Szkoty Prawa Rzymskiego, Warszawa 1224 września 2001 roku, «Zeszyty Prawnicze» 2.1/2002, s. 203-206.

Nadanie Jego Światobliwości Papieżowi Janowi Pawłowi II tytulu Doktora 'honoris causa' wszystkich dyscyplin Uniwersytetu Kardynata Stefana Wyszyńskiego, «Zeszyty Prawnicze» 2.1/2002, s. 215-224.

Diritto romano pubblico e privato. L'esperienza plurisecolare dello sviluppo del diritto europeo. III Miedzynarodowa Konferencjacja Romanistów w Jaroslawlu i Moskwie w dniach 25-30 czerwca 2003 roku, «Verba Legis» 4/2003, s. 12.

Profesor Tomasz Dybowski, «Zeszyty Prawnicze» 3.2/2003, s. 9-13.

Bibliografia publikacji Profesora Tomasza Dybowskiego, «Zeszyty Prawnicze» 3.2/2003, s. 14-20.

Diritto romano pubblico e privato. L'esperienza plurisecolare dello sviluppo del diritto europeo. III Miedzynarodowa Konferencja Romanistów w Jaroslawlu i Moskwie w dniach 25-30 czerwca 2003 roku, «Zeszyty Prawnicze» 4.1/2004, s.273-274.

'In memoriam' - Tomasz Dybowski (1923-2009), «Zeszyty Prawnicze» 10.1/2010, s. 357-359.

'In memoriam' - Andrzej Kremer (1961-2010), «Zeszyty Prawnicze» 10.1/2010, s. 359-361.

Czas cenniejszy od złota. Świętej Pamięci Księdza Profesora Ryszarda Rumianka (1947-2010), «Zeszyty Prawnicze» 11.2/2011, s. 9-12.

$W$ imię wspólnych wartości. Świętej Pamięci Prezydenta Lecha Kaczyńskiego (1949-2010), «Zeszyty Prawnicze» 11.3/2011, s. 9-12. 